\title{
SYMBIOTIC EFFECTIVENESS OF RHIZOBIUM LEGUMINOSARUM BV. VICIAE WITH PEA PLANTS AS INFLUENCED BY AZOTOBACTER CHROOCOCCUM
}

\author{
Stefan Martyniuk' ${ }^{1}$ Monika Kozieł', Anna Gałązka' \\ 1 Department of Agricultural Microbiology, Institute of Soil Science and Plant Cultivation, State Research \\ Institute, Czartoryskich 8, 24-100 Puławy, Poland, e-mail: sm@iung.pulawy.pl
}

Received: 2015.0713

Accepted: 2015.08.31

Published: 2015.10.01

\begin{abstract}
The aim of this work was to examine the effects of $A$. chroococcum on the proliferation of $R$. leguminosarum bv. viciae $(R l v)$ in a solid-carrier inoculant and on symbiotic effectiveness of $R l v$ with pea plants grown under laboratory and field conditions. In a laboratory experiment it was found that proliferation of both bacterial species, Rlv and A. chroococcum, in the dual-culture inoculants was efficient, and that $A$. chroococcum had no adverse effects on the development of the rhizobia $(R l v)$ in the solidcarrier inoculant. In a pot experiment the highest number of nodules was detected on roots of pea plants inoculated with the dual-culture inoculant containing $R l v$ and $A$. chroococcum, slightly lower numbers on pea roots inoculated with the mono-culture inoculum of $R l v$ and almost no nodules were found on the roots of pea un-inoculated (control treatment) with the bacteria. In the micro-plot experiment conducted in the years 2011-2012 pre-sowing inoculation of pea seeds with the mono-culture inoculant of $R l v$ or with the mixed inoculant of $R l v$ and $A$. chroococcum slightly increased nodule numbers/plant, pod numbers/plant and seed numbers/pod, as compared to the un-inoculated control, but these differences were not reflected in pea seed yields $/ \mathrm{m}^{2}$, which were similar in all treatments.
\end{abstract}

Keywords: Azotobacter, Rhizobium, field pea, inoculants, nodulation, yield.

\section{INTRODUCTION}

Pre-sowing seed inoculation of legume crops with symbiotic bacteria, commonly known as rhizobia, is an important agricultural practice intended to increase nitrogen fixation and seed yields of these crops [Bushan 1998, Graham, Vance 2003, Deaker et al. 2004]. Yield increases due to this treatment depend mainly on the number and effectiveness of indigenous populations rhizobia in soil, but also other factors such as soil physicochemical constrains, soil nitrogen availability and climatic conditions can affect responses of legumes to rhizobial inoculants [Singleton et al. 1992, Graham, Vance 2003, Martyniuk et al. 2014]. When soils are deficient or contain low populations of rhizobia, seeds or soil inoculation with these bacteria usually results in an improved nodulation and significant yield increases of legumes [Thies at al.1991, Singleton et al., 1992,
Bushan 1998]. However, when adequate numbers of symbiotically effective rhizobia are present in soils, such treatments usually do not lead to improved plant growth and higher seed yields of legume crops. The results of greenhouse and field studies indicate that as few as 10-20 cells of indigenous rhizobia in $1 \mathrm{~g}$ of soil can markedly reduce or even eliminate beneficial responses of various legumes to inoculants containing symbiotic bacteria [Jensen 1987, Thies at al. 1991, Singleton et al., 1992, Cheminingwa, Vessey 2006, Martyniuk et al. 2013]. In Poland most of soils are colonized with moderate or high, up to $8.5 \times 10^{5}$ cells g $^{-1}$ of soil, populations of Rhizobium leguminosarum bv. viciae - the symbiotic bacteria of pea [Martyniuk et al. 2005]. Various strategies have been studied to improve efficacy of rhizobium inoculants applied to legumes grown on soils colonized with high natural populations of symbiotic bacteria and those include: selection of 
rhizobial strains for increased $\mathrm{N}_{2}$ fixation capacity or higher competitive ability, in-furrow application of liquid inoculants or application of mixed inoculants of rhizobia with other plant growth promoting bacteria, like Azotobacter, Azospirillum and Pseudomonas [Burns et al. 1981, Bashan 1998, Graham, Vance 2003, Deaker et al. 2004].

Bacteria belonging to the genus Azotobacter, with the species $A$. chroococcum most commonly colonizing various soils all over the world, are able to fix atmospheric nitrogen as well as beneficially effect seed germination and plant growth mainly due to their ability to produce various biologically active substances like phytohormones (IAA, cytokinins, giberelins), vitamins, siderophores and antifungal compounds [Harper, Lynch 1979, Neito, Frankenberger 1989, Gonzales-Lopez et al. 1991, Bushan 1998, Kumar et al. 2000]. Studies conducted by Burns et al. [1981], ElBahrawy [1983] and Rodeles et al. [1999] have shown that mixed inoculants containing rhizobia and Azotobacter spp. were superior as compared to rhizobial inoculants with respect to their influence on nodulation intensity, efficiency of nitrogen fixation and yields of some legumes, however, these effects were obtained under gnotobiotic conditions or in soil-less pot experiments.

The aim of this work was to examine effects of Azotobacter chroococcum on proliferation of Rhizobium leguminosarum bv. viciae $(R l v)$ in a solid-carrier inoculant and on symbiotic effectiveness of $R l v$ with pea plants grown under laboratory and field conditions.

\section{MATERIAL AND METHODS}

\section{Biological materials}

The Culture Collection of $\mathrm{N}_{2}$-fixing Bacteria belonging to the Department of Agricultural Microbiology of the Institute of Soil Sc. and Plant Cultivation in Puławy was the source of the bacteria: $R$. leguminosarum bv. viciae $(R l v)$, strain GGL and Azotobacter chroococcum strain 17/08. Stock cultures of $R l v$ were maintained at $4{ }^{\circ} \mathrm{C}$ on slants of yeast extract-mannitol agar (YEMA) supplemented with $3 \mathrm{~g} \mathrm{CaCO}_{3} 1^{-1}$ [Vincent, 1970]. Yeast extract-mannitol broth (YEMB) was used to prepare liquid cultures of $R l v$. Numbers of viable cells (colony forming units - CFU) of the rhizobia in liquid cultures, on inoculated pea seeds and in soil-state inoculants were counted by standard dilution plate procedures on YEMA containing $25 \mathrm{mg} \cdot 1^{-1}$ of Congo red [Vincent, 1970, Martyniuk et al., 2013]. A. chroococcum strain 17/08 was cultured in Burk's N-free liquid medium and this medium supplemented with agar was also used to maintain stock cultures of A. chroococcum and to count CFU numbers of this bacterium in liquid cultures, on pea seeds and in solid-sate inoculants [Martyniuk et al. 2013]. Polish cultivar "Grapis" of field pea [Pisum sativum (L)] was grown in a pot experiment and under field conditions in two micro-plot experiments conducted in 2011 and 2012.

\section{Preparation of solid-carrier bacterial inoculants}

Finely milled brown coal, mixed with $1 \%$ of $\mathrm{CaCO}_{3}$ to adjust the $\mathrm{pH}$ to 6.6-6.8, was used as the bacterial carrier in all solid-state inoculants applied in these studies. The carrier material was obtained from a commercial producer of rhizobial inoculants in Poland. Portions of moistened $(10 \%)$ carrier weighing $200 \mathrm{~g}$ were placed into polypropylene bags and sterilized by autoclaving in $121^{\circ} \mathrm{C}$ for $60 \mathrm{~min}$. Batches of $50 \mathrm{ml}$ of YEMB medium and $\mathrm{N}$-free Burk's medium were used to culture Rlv and A. chroococcum 17/08, respectively, in 250-ml Erlenmeyer flasks on a shaker platform rotating at $100 \mathrm{rpm}$. Cultures of the bacteria in the late log-phase of growth with approximately $1-3 \times 10^{9} \mathrm{CFU} \mathrm{ml}{ }^{-1}$ were used to inoculate bags containing sterile carrier. To prepare mixed inoculants bags with sterile carrier were inoculated with $50 \mathrm{ml}$ of broth cultures of $R l v$ and 50 $\mathrm{ml}$ broth culture of $A$. chroococcum. In the case of inoculants containing $R l v$ alone $50 \mathrm{ml}$ of Burk's liquid medium was added instead of $A$. chroococcum culture. The inoculants (in 3 replicated bags) were incubated for 7 days at $28{ }^{\circ} \mathrm{C}$ and at room temperature for further three weeks. Every week the quality of these inoculants was checked by counting CFU numbers of $R l v$ on YEMA-Congo red plates and A. chroococcum on N-free Burk's agar plates as described above. At the end of the incubation period symbiotic effectiveness of the inoculants was assessed in a pot experiment with pea plants.

\section{Pot experiment}

Plastic pots $(1000 \mathrm{ml})$ containing perlite moistened with $300 \mathrm{ml}$ of $\mathrm{N}$-free liquid medium to support plant growth were used in this experiment. Pea seeds cv. Grapis were surface disin- 
fected with $5 \% \mathrm{H}_{2} \mathrm{O}_{2}(10 \mathrm{~min}$.), thoroughly rinsed with distilled water and allowed to dry. Disinfected seeds were then treated with the inoculant containing $R l v$ or with the mixed inoculant consisting of the rhizobia and $A$. chroococcum. The inoculants were applied at the rate of $2 \mathrm{~g}$ per $100 \mathrm{~g}$ of pea seeds. In the control treatment pea seeds were coated with sterile carrier. Five treated pea seeds were planted into each pot, in five replications for each treatment, and after the emergence four uniform seedlings were left in each pot. The pots were placed in a growth chamber (Heresus HPS $1500-2000$ ) running at $16 \mathrm{~h} / 8 \mathrm{~h}$ day/night regime and temperature $22{ }^{\circ} \mathrm{C} / 15^{\circ} \mathrm{C}$, respectively. After four weeks the experiment was terminated to count the numbers of nodules on root systems of each seedling and to determine fresh and dry mass of roots and shoots and the number of $A$. chroococcum CFU on pea roots.

\section{Micro-plot experiments}

These experiments, arranged in a randomized split-plot design, were carried out during the 2011 and 2012 growing seasons on a field at the Experimental Station belonging to the Institute of Soil Science and Plant Cultivation in Puławy. The soil (sandy loam, Haplic Luvisol) on this field had the following basic characteristics: $\mathrm{pH}\left(\mathrm{H}_{2} \mathrm{O}\right) 6.2$, $1 \%$ org. C, $60 \%$ sand, $31 \%$ silt and $9 \%$ clay. The soil was colonized with about $2 \times 10^{3}$ cells g ${ }^{-1}$ soil d.m. of rhizobia nodulating pea, as assessed by plant infection bio-test with pea seedlings and the most probable number estimation [Vincent 1970, Martyniuk et al. 2005], and with low populations, about 10-12 CFU g ${ }^{-1}$ soil d.m., of bacteria belonging to the genus Azotobacter spp., as determined by plate dilution method on Burk's agar medium [Martyniuk, Martyniuk 2002).

The experiments included the following treatments, each consisting of four replicated plots: I - no inoculation (control), pea seeds, cv. Grapis, treated with the carrier used to prepare the bacterial inoculants, II - pea seeds treated with the inoculant containing strain GGL of $R$. leguminosarum bv. viciae (Rlv) alone, III - pea seeds treated with the mixed inoculant of Rlv strain GGL and A. chroococcum 17/08. Before inoculation all pea seeds were treated with a commercial chemical seed dressing. The bacterial inoculants, prepared as described above, were applied at the rate of 20 $\mathrm{g}$ per $1 \mathrm{~kg}$ of pea seeds. Seeds were hand sown on $1 \mathrm{~m}^{2}$ plots consisting of 3 rows spaced $30 \mathrm{~cm}$ apart. Soil fertilization and other agro-technical practices followed general recommendations for field pea cultivation.

At the flowering stage five pea plants from each replicated plots were dug out using a shovel to assess root systems for nodulation intensity (nodule numbers) and to count the total number of bacteria belonging the genus Azotobacter in rhizosphere soil closely adhering to pea roots as described in Martyniuk at al. [2013]. At the physiological maturity stage all pea plants from the central rows were collected to determine seed yields and some yield components. All data were subjected to the analysis of variance using Anova test.

\section{RESULTS AND DISCUSSION}

The solid-state carrier - finally milled brown coal - used in this study was a suitable material for preparation of inoculants containing monoculture of $R$. leguminosarum bv. viciae $(R l v)$ or mixed culture of Rlv and A. chroococcum. The highest numbers of the bacteria, 3.1-6.0 $\times 10^{10}$ CFU g ${ }^{-1}$ of inoculant, were found after 14 days of incubation and then slightly decreased, but after 30 days of incubation the numbers of these bacteria still exceeded $10^{10} \mathrm{CFU}$ in $1 \mathrm{~g}$ of the carrier (Table 1). Proliferation of Rlv in the mono-culture inoculant was similar to that in the dual-culture inoculant with $A$. chroococcum. Only after 7 days of incubation at $28{ }^{\circ} \mathrm{C}$ the number $\left(6.8 \times 10^{9} \mathrm{CFU}\right.$ $\left.\mathrm{g}^{-1}\right)$ of $R l v$ in the monoculture inoculant was significantly higher than the number $\left(4.7 \times 10^{9} \mathrm{CFU}\right.$ $\mathrm{g}^{-1}$ ) of this bacterium in the dual-culture inoculant (Table 1). Multiplication of A. chroococcum in the mixed culture with $R l v$ was also intensive, increasing from $2.5 \times 10^{6} \mathrm{CFU} \mathrm{g}^{-1}$ of inoculant at the beginning of the incubation time to $1.2 \times 10^{10}$ CFU g ${ }^{-1}$ after 30 days of incubation. The results of this laboratory experiment indicate that proliferation of both bacterial species, $R l v$ and $A$. chroococcum, in the dual-culture inoculants was efficient, and that $A$. chroococcum had no adverse effects on the development of the rhizobia $(R l v)$ in the solid-carrier inoculant. We used sterile (autoclaved) powdered brown coal as a carrier to prepare the inoculants and this was probably the main factor facilitating multiplication of $R l v$ and A. chroococcum in the carrier. It has been shown that multiplication of various species of rhizobia and the final quality of inoculants based on sterilized (by gamma irradiation or by autoclaving) 
Table 1. Proliferation (CFU in $1 \mathrm{~g}$ of carrier dry weight $\pm \mathrm{SD}$ ) of Rhizobium leguminosarum bv. viciae (Rlv) and A. chroococcum in mono-culture $(R l v)$ or dual-culture inoculants $(R l v+A$. chroococcum $)$

\begin{tabular}{|l|c|c|c|c|c|}
\hline \multicolumn{1}{|c|}{ Bacteria } & \multicolumn{5}{c|}{ Incubation time [days] } \\
\cline { 2 - 6 } & 1 & 7 & 14 & 21 & 30 \\
\hline $\begin{array}{l}\text { Numbers of } R / v \text { in mono-culture } \\
\text { inoculant }\end{array}$ & $2.2( \pm 0.2) \times 10^{7} \mathrm{a}^{*}$ & $6.8( \pm 0.7) \times 10^{9} \mathrm{a}$ & $6.0( \pm 0.5) \times 10^{10} \mathrm{a}$ & $3.1( \pm 0.4) \times 10^{10} \mathrm{a}$ & $2.0( \pm 0.5) \times 10^{10} \mathrm{a}$ \\
\hline $\begin{array}{l}\text { Numbers of } R / v \text { in dual-culture } \\
\text { inoculant }\end{array}$ & $2.1( \pm 0.2) \times 10^{7} \mathrm{a}$ & $4.7( \pm 0.5) \times 10^{9} \mathrm{~b}$ & $5.5( \pm 0.6) \times 10^{10} \mathrm{a}$ & $2.8( \pm 0.2) \times 10^{10} \mathrm{a}$ & $1.4( \pm 0.1) \times 10^{10} \mathrm{a}$ \\
\hline $\begin{array}{l}\text { Numbers of } A \text {. chroococcum in } \\
\text { dual-culture inoculant }\end{array}$ & $2.5( \pm 0.2) \times 10^{7}$ & $4.3( \pm 0.4) \times 10^{9}$ & $3.1( \pm 0.3) \times 10^{10}$ & $1.1( \pm 0.1) \times 10^{10}$ & $1.2( \pm 0.2) \times 10^{10}$ \\
\hline
\end{tabular}

* Values in columns followed by the same letter are not significantly different $(P=0.05)$.

peat as the carrier were superior in comparison to inoculants prepared with the use of unsterile peat [Vincent 1970, Somasegaran 1985, Deaker et al. 2004].

The quality of the inoculants prepared in this study, particularly their symbiotic effectiveness, was checked in the pot experiment with pea plants (Table 2). The highest number of nodules was detected on roots of pea plants inoculated with the dual-culture inoculant containing $R l v$ and $A$. chroococcum, slightly lower numbers on pea roots inoculated with the mono-culture inoculant of $R l v$ and almost no nodules were found on roots of pea un-inoculated (control treatment) with the bacteria (Table 2). Few nodules detected on some pea plants in the control treatment was probably a result of cross-contamination or incomplete seed sterilization at the beginning of the experiment. A. chroococcum occurred only on pea roots inoculated with the inoculant containing this bacterium (Table 2). Pea plants in the uninoculated treatment showed symptoms of $\mathrm{N}$ deficiency due to almost complete lack of symbiotic nodules on their roots and for this reason fresh and dry weights of pea shoots in this treatment were significantly lower than shoots of plants inoculated with the bacteria (Table 2). Only pea plants inoculated with the dual-culture inoculant $(R l v+A$. chroococcum $)$ had significantly higher fresh and dry weight of roots (Table 2) than the un-inoculated plants or plants inoculated with the mono-culture inoculant $(R l v)$, indicating stimulation of pea root growth by A. chroococcum the bacterium which has been shown to produce various biologically active substances, including plant hormones [Neito, Frankenberger 1989, Gonzales-Lopez et al. 1991, Bushan 1998, Kumar et al. 2000]. The increased size of root systems of pea plants treated with the inoculant containing A. chroococcum creating more infection sites for initiation of root nodules by $R l v$ was probably the main reason for the improved nodulation of pea plants in this treatment as compared to pea plants inoculated with the mono-culture inoculant containing Rlv only (Table 2).

In the micro-plot experiment conducted in the years 2011-2012 pre-sowing inoculation of pea seeds with the mono-culture inoculant of $R l v$ or with the mixed inoculant of $R l v$ and A. chroococcum slightly increased nodule numbers plant ${ }^{-1}$, pod numbers plant ${ }^{-1}$ and seed numbers pod $^{-1}$, as compared to the un-inoculated control, but these differences were not reflected in seed yields square $\mathrm{m}^{-1}$, which were similar in all treatments (Table 3).

Previous studies with different legumes have shown that pre-sowing seed or soil inoculation with symbiotic root-nodule bacteria improved nodulation and seed yields of these crops when they were grown on soils deficient in infective

Table 2. Effect of seed treatment with mono-culture inoculant of Rhizobium leguminosarum bv. viciae (Rlv) or with dual-culture inoculant of Rlv+Azotobacter chroococcum on counts of A. chroococcum, plant growth and nodulation of pea in pot experiment

\begin{tabular}{|c|c|c|c|c|c|c|}
\hline \multirow{2}{*}{ Treatments } & \multirow{2}{*}{$\begin{array}{l}\text { Number of } \\
\text { A. chroococcum } \\
\text { CFU/g roots DW }\end{array}$} & \multirow{2}{*}{$\begin{array}{c}\text { Numbe of } \\
\text { nodules/plant }\end{array}$} & $\begin{array}{c}\text { Shoot fresh } \\
\text { weight }\end{array}$ & $\begin{array}{c}\text { Shoot } \\
\text { dry weight }\end{array}$ & $\begin{array}{c}\text { Root fresh } \\
\text { weight }\end{array}$ & $\begin{array}{c}\text { Root } \\
\text { dry weight }\end{array}$ \\
\hline & & & \multicolumn{4}{|c|}{$\mathrm{g} /$ plant } \\
\hline No inoculation & 0 & $0.3 \mathrm{a}^{*}$ & $1.03 \mathrm{a}$ & $0.15 \mathrm{a}$ & $2.3 \mathrm{a}$ & $0.15 \mathrm{a}$ \\
\hline Rhizobium (RIV) & 0 & $36 \mathrm{~b}$ & $2.05 \mathrm{~b}$ & $0.31 \mathrm{~b}$ & $2.4 \mathrm{a}$ & $0.14 a$ \\
\hline$R / v+$ A. chroococ. & 352 & $43 \mathrm{c}$ & $2.10 \mathrm{~b}$ & $0.32 \mathrm{~b}$ & $2.8 \mathrm{~b}$ & $0.18 b$ \\
\hline
\end{tabular}

${ }^{*}$ Values in columns followed by the same letter are not significantly different $(P=0.05)$. 
Table 3. Effect of seed treatment with mono-culture inoculant of Rhizobium leguminosarum bv. vicae (Rlv) or with dual-culture inoculant of $R l v+$ Azotobacter chroococcum on rhizosphere counts of $A$. chroococcum, nodulation, yield components and seed yields of pea grown in micro-plot experiments (Means for 2011 and 2012)

\begin{tabular}{|l|c|c|c|c|c|}
\hline \multicolumn{1}{|c|}{ Treatments } & $\begin{array}{c}\text { Number of Azotobacter spp. } \\
\text { CFU/g soil DW }\end{array}$ & $\begin{array}{c}\text { Number of } \\
\text { nodules/plant }\end{array}$ & $\begin{array}{c}\text { Number of } \\
\text { pods/plant }\end{array}$ & $\begin{array}{c}\text { Number of } \\
\text { seed/pod }\end{array}$ & $\begin{array}{c}\text { Seed weight } \\
\mathrm{g}^{2} \mathrm{~m}^{2}\end{array}$ \\
\hline No inoculation & $30 \mathrm{a}$ & $22.1 \mathrm{a}^{*}$ & $8.0 \mathrm{a}$ & $3.7 \mathrm{a}$ & $496 \mathrm{a}$ \\
R. I. bv. viciae & $32 \mathrm{a}$ & $25.0 \mathrm{a}$ & $8.2 \mathrm{a}$ & $3.9 \mathrm{a}$ & $494 \mathrm{a}$ \\
RIV + A. chroococ. & $68 \mathrm{~b}$ & $24.1 \mathrm{a}$ & $9.0 \mathrm{a}$ & $4.0 \mathrm{a}$ & $500 \mathrm{a}$ \\
\hline
\end{tabular}

* Values in columns followed by the same letter are not significantly different $(P=0.05)$.

strains of rhizobia or on soils containing low numbers of these bacteria [Jensen 1987, Thies at al. 1991, Singleton et al. 1992, Cheminingwa, Vessey 2006]. This was not a case with the soil used in our micro-plot experiments. This soil was colonized with relatively high population of pea rhizobia $\left(2 \times 10^{3}\right.$ cells g ${ }^{-1}$ soil d.m. $)$ which effectively nodulated pea roots and provided pea plants with sufficient amount of symbiotic $\mathrm{N}$ in the control treatment (Table 3), and thus additional application of pea rhizobia as seed inoculants did not increase seed yields. Similar results were obtained with yellow lupine grown on the same soil, which was also colonized with high population of rhizobia nodulating lupine [Martyniuk et al. 2013].

Results shown in Table 3 indicate that the dual-culture inoculant containing $R l v$ and $A$. chroococcum was generally not superior in comparison to the inoculant containing pea rhizobia $(R l v)$ alone. In pot experiments conducted under gnotobiotic conditions or with the use of sterile soils [Burns et al. 1981, El-Bahrawy 1983, Rodelas et al., 1999] it has been shown that nodulation intensity, efficiency of nitrogen fixation and yields of some legumes inoculated with mixed cultures of rhizobia and other beneficial microorganisms, like Azotobacter spp. and Azospirillum spp., were higher as compared to those inoculated with the rhizobia alone. These findings are in accordance with the results of our pot experiment. However, the results of our micro-plot experiments with unsterile soil naturally colonized with various soil microorganisms indicate that the addition $A$. chroococcum to the inoculant did not improve symbiotic relationships between $R l v$ and pea plants (Table 3 ).

The prerequisite for obtaining positive results of seed or soil inoculation with beneficial microorganisms is their establishment and proliferation on roots or in the rhizosphere soil [Bashan 1998, Rodelas et al. 1999]. To find out if A. chroococcum introduced onto pea seeds proliferated in the rhizosphere soil of this crop we counted the total numbers Azotobacter spp. in the rhizosphere soil of pea plants inoculated the tested inoculants. The results presented in Table 3 show that the number of Azotobacter spp. in the rhizosphere soils of pea treated with the inoculant containing $A$. chroococcum significantly increased as compared to the control treatment or to pea inoculated with the mono-culture inoculant $(R l v)$, but this number remained low $\left(68 \mathrm{CFU} \mathrm{g}^{-1}\right)$. Competitive interactions with other soil microorganisms and slightly acid $\mathrm{pH} 6.2$ of the soil used in our studies were probably the main reasons for the limited proliferation of A. chroococcum in the rhizosphere soil of pea plants. Bacteria of the genus Azotobacter prefer neutral soils in which their numbers range from several hundreds to $10^{4} \mathrm{CFU}$ in $\mathrm{g}$ of soil [Bashan 1998, Rodelas et al. 1999, Martyniuk, Martyniuk 2002]. The soil used in our studies was slightly acidic (pH 6.2) and this was an important factor limiting proliferation of $A$. chroococcum in the rhizosphere soil of pea plants, but also other factors, particularly competitive interactions with other soil microorganisms, were probably crucial in this respect [Dobbelaere et al. 2003, Rodelas et al. 1999].

\section{CONCLUSION}

The main conclusion from this study is that when pea is grown on a soil rich in natural populations of symbiotic rhizobia $(R l v)$ neither presowing seed inoculation with pea rhizobia nor with dual-culture inoculant of these bacteria and A. chroococcum can improve nodulation and seed yields of this legume crop.

\section{REFERENCES}

1. Bashan Y. 1998. Inoculants of plant growth-promoting bacteria for use in agriculture. Biotech. Adv. 16, 729-770. 
2. Burns T.A, Bishop P.E., Izrael D.W. 1981. Enhanced nodulation of leguminous plant roots by mixed cultures of Azotobacter vinelandi and Rhizobium. Plant Soil, 62, 399-412.

3. Cheminingwa G.N., Vessey J.K. 2006. The abundance and efficacy of Rhizobium leguminosarum bv. viciae in cultivated soils of the eastern Canadian prairie. Soil Biol. Biochem. 38, 294-302.

4. Deaker R., Roughley R.J., Kennedy I.R. 2004. Legume seed inoculation technology - a review. Soil Biol. Biochem. 36, 1275-1288.

5. El-Bahrawy S.A. 1983. Associative effect of mixed cultures of Azotobacter and different rhizosphere fungi with Rhizobium japonicum on nodulation and symbiotic nitrogen fixation of soybean. Zentralbl. Mikrobiol. 138, 443-440.

6. Gonzales-Lopez J., Martinez-Toledo M.V., Reina S., Salmeron V. 1991. Root exudates of maize and production of auxins, gibberellins, cytokinins, amino acids and vitamins by Azotobacter chroococcum in chemically-defined media and dialysed-soil media. Toxic. Environ. Chem. 33(1-2), 69-78.

7. Graham P.H., Vance C.P. 2003. Legumes: importance and constrains to greater use. Pl. Physiol. 131, 872-877.

8. Harper S.H., Lynch J.M. (1979): Effect of $A$. chroococcum on barley and seed germination and seedling development. Journal of General Microbiology, 112, 45-50.

9. Jensen E.S., (1987): Inoculation of pea by application of Rhizobium in the planting furrow. Plant Soil 97, 63-70.

10. Kumar V., Kumar-Aggarwal N., Singh B.P. 2000. Performance and persistence of phosphate solubilizing Azotobacter chroococcum in wheat rhizosphere. Folia Microbiol. 45(4), 343-347.
11. Martyniuk S., Martyniuk M. (2002): Occurrence of Azotobacter spp. in some Polish soils. Pol. J. Environ. Stud. 12(3), 371-374.

12. Martyniuk S., Oron J., Martyniuk M. 2005. Diversity and numbers of root-nodule bacteria (rhizobia) in Polish soils. Acta Soc. Bot. Pol. 74(1), 83-86.

13. Martyniuk S., Kozieł M., Gębala B. 2013. Response of yellow lupine to seed inoculation with Bradyrhizobium sp. (Lupinus) and with mixed inoculants of Bradyrhizobium sp. and Azotobacter chroococcum. J. Food Agric. Environ. 11(2), 393-396.

14. Neito K.F., Frankenberger, W.T. 1989. Biosynthesis of cytokinins by Azotobacter chroococcum. Soil Biol. Biochem. 21, 967-972.

15. Rodelas B., Gonzales-Lopez J., Pozo C., Salmeron V., Martinez-Toledo M.V. 1999. Response of faba bean (Vicia faba L.) to combined inoculation with Azotobacter and Rhizobium leguminosarum bv. viceae. Appl. Soil Ecol. 12, 51-59.

16. Singleton P.W., Bohlool B.B., Nakao P.L. 1992. Legume response to rhizobial inoculation in the Tropics: myth and realities. In: Lai R., Sanchez P. (Eds) Myths and science of the soils of the tropics. Madison, WI, SSSA Spec. Publ. No. 29, 135-155.

17. Somasegaran P. 1985. Inoculant production with diluted liquid culture of Rhizobium spp. and autoclaved peat: evaluation of diluents, Rhizobium spp., peats, starility requirements, storage, and plant effectiveness. Appl. Environ. Microbiol. 50, 398-405.

18. Thies J.E., Singleton P.W., Bohlool B.B. 1991. Influence of the size of indigenous rhizobial populations on establishment and symbiotic performance of introduced rhizobia on field-grown legumes. Appl. Environ. Microbiol. 57, 19-28.

19. Vincent J.M. 1970. A manual for practical study of root-nodule bacteria., Blackwell Scientific Publications, Oxford, pp. 164. 